\title{
Retroauricular Lymph Node
}

National Cancer Institute

\section{Source}

National Cancer Institute. Retroauricular Lymph Node. NCI Thesaurus. Code C142313.

The lymph nodes located immediately posterior to the ear; also known as the mastoid lymph nodes or the posterior auricular lymph nodes. 